\title{
Pulmonary and atrial resection and reconstruction for sarcoma with intracardiac extension
}

\author{
Kohei Hashimoto, MD, ${ }^{a}$ William Stansfield, MD, ${ }^{\mathrm{b}}$ and Shaf Keshavjee, MD, ${ }^{\mathrm{a}}$ Toronto, Ontario, Canada
}

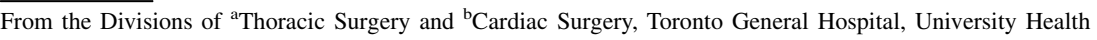
Network, Toronto, Ontario, Canada.

K.H. is supported by a fellowship grant from the Mitsukoshi Health, Welfare Foundation, Tokyo, Japan, and the Ishidsu Shun Memorial Scholarship, Tokyo.

Read at the American Association of Thoracic Surgery 2015 Focus on Thoracic Surgery: Technical Challenges and Complication, Boston, Massachusetts, October 23-24, 2015.

Disclosures: Authors have nothing to disclose with regard to commercial support.

Received for publication Aug 1, 2016; revisions received Nov 15, 2016; accepted for publication Dec 4, 2016; available ahead of print Jan 12, 2017.

Address for reprints: Shaf Keshavjee, MD, Division of Thoracic Surgery, Toronto General Hospital, 190 Elizabeth

St, RFE 1-408, Toronto, Ontario M5G 2C4, Canada (E-mail: Shaf.Keshavjee@uhn.ca).

J Thorac Cardiovasc Surg 2017;153:e61-3

$0022-5223 / \$ 36.00$

Copyright (c) 2016 by The American Association for Thoracic Surgery

http://dx.doi.org/10.1016/j.jtcvs.2016.12.007
}

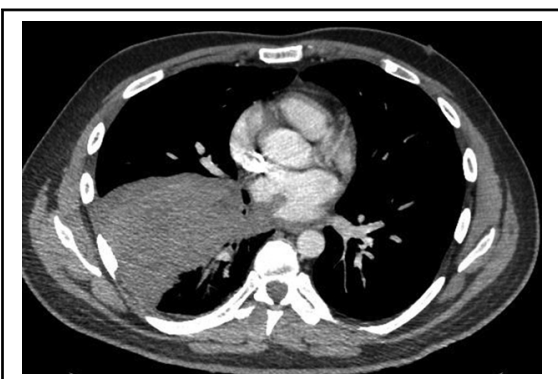

A pulmonary metastasis of sarcoma with extensive cardiac extension in the left atrium.

\section{Central Message}

Open atrial resection may be a viable option to achieve complete resection for pulmonary metastasis with extensive cardiac invasion

See Editorial Commentary page e65.
Soft tissue sarcomas are rare tumors that arise from mesenchymal cells at all body sites. The primary metastatic site of soft tissue sarcomas is the lung, a location that leads to significant morbidity and mortality. ${ }^{1}$ There have been no studies that compare pulmonary metastasectomy with no treatment or chemotherapy or radiation therapy alone. A multi-institutional retrospective study of pulmonary metastasectomy for soft tissue sarcoma showed that the 5-year survival was $38 \%$. $^{2}$ Although direct comparisons are difficult, the survival of untreated lung metastases is typically less than 2 years. ${ }^{3}$ Therefore, the surgical resection of pulmonary metastases of soft tissue sarcoma may be a reasonable option for a selected population.

\section{CASE}

A 38-year-old man presented with hemoptysis. He had a history of resection of malignant fibrous histiocytoma of the right hip 16 months ago. A computed tomography (CT) showed a right lower lobe pulmonary lesion measuring $11 \mathrm{~cm}$ in diameter and invading the left atrium (Figure 1, $A)$ and a 4-cm lesion in the left lower lobe on the diaphragm (Figure 1, B). For palliative purposes, $20 \mathrm{~Gy}$ of radiation was applied to the right pulmonary metastasis. After hemoptysis subsidized, low-molecular-weight heparin was administered for the prevention of thrombus, followed by 6 cycles of chemotherapy (ifosfamide and doxorubicin [Adriamycin; Bedford Laboratories, Bedford, Mass]). At this time, the primary lesion had been controlled for 18 months and there were no extrapulmonary metastases. A post-chemoradiation CT scan showed significantly decreased tumor size, but the right lower lobe lesion was $7.5 \mathrm{~cm}$ in diameter and a left atrial invasion was present (Figure 1,C). The left lower lobe lesion was $1.8 \mathrm{~cm}$ in diameter (Figure 1,D). We elected for surgical resection because sizable disease persisted after systemic therapy. Furthermore, the intracardiac lesion presented a significant ongoing risk for thrombosis and stroke. These oligometastases were assessed to be technically amenable to complete resection.

A clamshell incision was selected, which allowed for excellent exposure of bilateral tumors and facilitated careful dissection with minimal manipulation (Video 1). We deflated the right lung. We then dissected the right hilum and encircled the right main pulmonary artery with a tourniquet, ready to be snared later. Before manipulation of the inferior vein and left atrium, we initiated cardiopulmonary bypass and stopped ventilation to both lungs. We then dissected Waterston's interatrial groove and identified the tumor. After crossclamp induction of cardioplegic arrest, we opened the left atrium and resected the tumor with an approximately 2 -cm margin (Figure 2, A). The right superior pulmonary vein was not involved. Intraoperative frozen section confirmed that the atrial margin was negative for malignancy. A primary closure would compromise the 


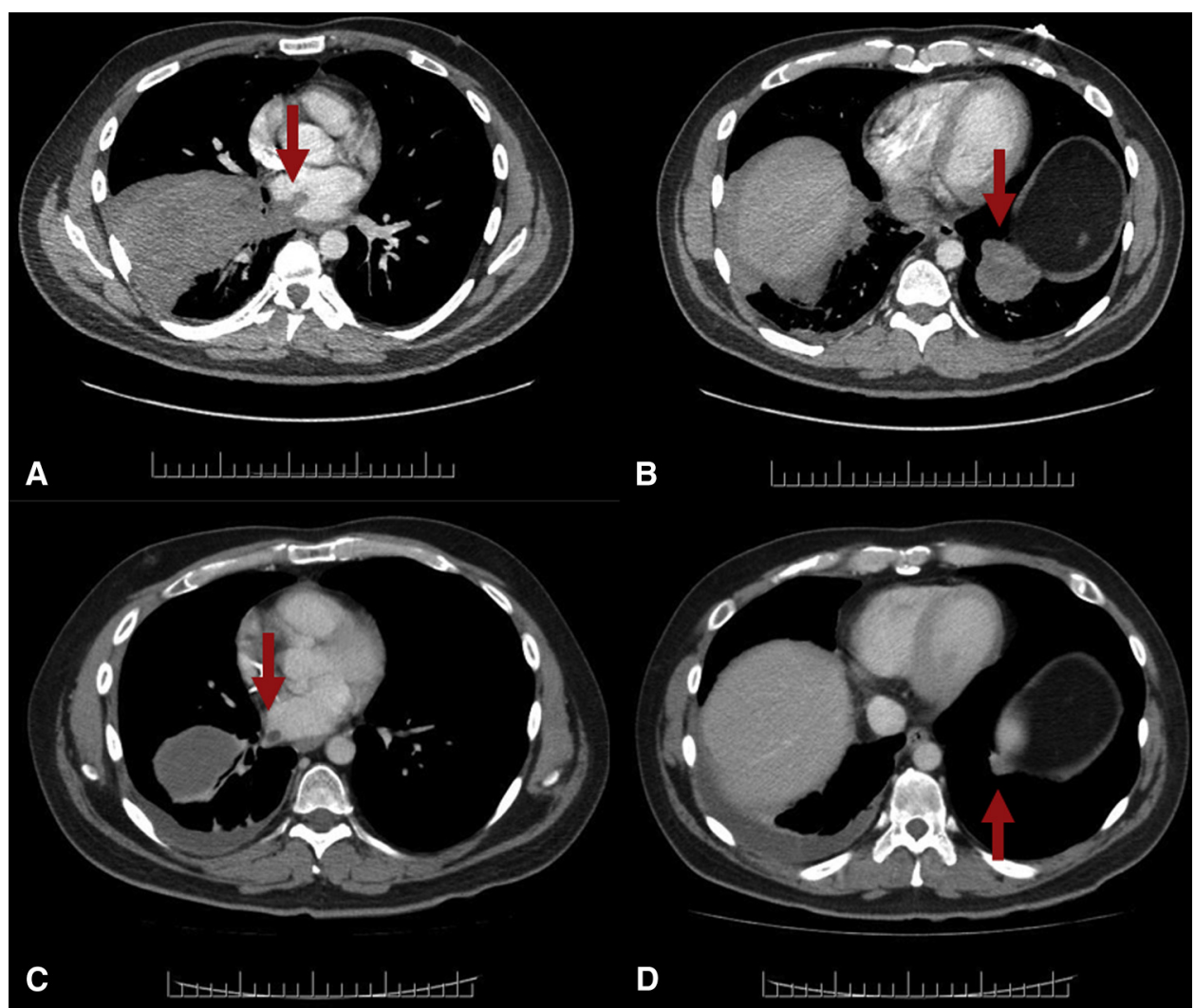

FIGURE 1. Chest CT. Before (A, B) and after (C, D) chemoradiotherapy. A, Right pulmonary lesion $11 \mathrm{~cm}$ in diameter with a left atrial invasion (arrow). B, Left lower lobe lesion $4 \mathrm{~cm}$ in diameter on the diaphragm (arrow). C, Shrunken tumor $(7.5 \mathrm{~cm})$ with remaining atrial invasion (arrow). D, Left lower lobe lesion reduced to $1.8 \mathrm{~cm}$ in diameter (arrow). Each scale in images represents $1 \mathrm{~cm}$.

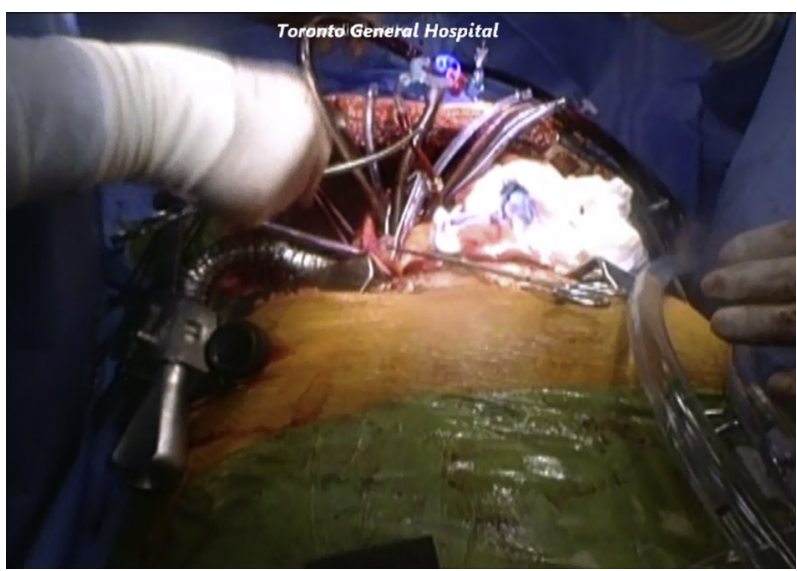

VIDEO 1. (1) We deflated the right lung. We then dissected the right hilum and encircled the right main pulmonary artery with a tourniquet. (2) Before manipulation of the inferior vein and left atrium, we put the patient on cardiopulmonary bypass and stopped ventilation to both lungs. (3) We then dissected Waterston's interatrial groove and identified the tumor protruding into the left atrium through the inferior pulmonary vein. (4) After the crossclamp induction of cardioplegic arrest, we opened the left atrium and resected the tumor with an approximately 2 -cm margin. The right superior pulmonary vein was not involved. Intraoperative frozen-section confirmed that the atrial margin was negative. (5) The atrial wall defect was closed using an autologous pericardial patch. (6) The left atrium was allowed to fill and de-air as we finished the closure. After further de-airing of the heart, the crossclamp was removed. (7) We snared the right main pulmonary artery to control flow from the open pulmonary side of the atrium. We then weaned from cardiopulmonary bypass, ventilating only the left lung and keeping the right lung deflated for the subsequent lobectomy. We then also over-sewed the atrial resection stump to control the bleeding through the right lung due to bronchial circulation. (8) We performed a wedge resection of the left lower lobe tumor while the left lung was ventilated, with a brief apneic period for the actual stapling of the wedge resection. (9) We then decannulated. Pump time was 69 min, and crossclamp time was 39 min. (10) We then completed the right lower lobectomy. (11) The pulmonary artery and bronchus of the right lower lobe were transected with staplers. (12) The remaining right lung inflated without difficulty. (13) Specimen of right lower lobe. The intact tumor is seen protruding from the end of vein cuff. Video available at: http://www.jtcvsonline.org/article/S0022-5223(16)31670-1/addons. 


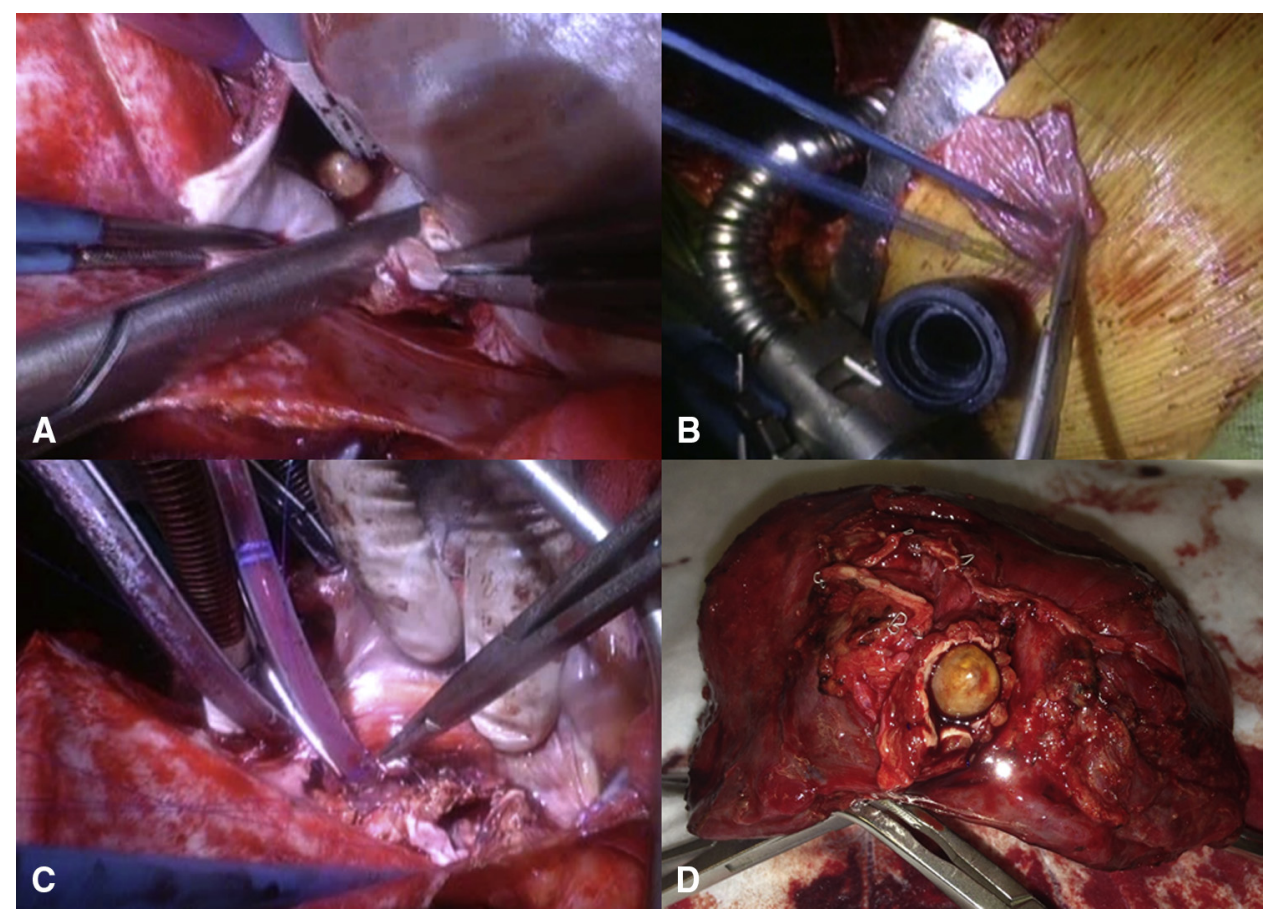

FIGURE 2. Intraoperative procedures. A 2 -cm margin was secured using an open atrial resection technique with confirmed negative margin using intraoperative frozen-section diagnosis (A). Autologous pericardial patch was obtained (B) and anastomosed to the atrial defect (C). An intact tumor was protruding into the left atrium in the resected specimen (D).

size of the atrial chamber. Thus, we closed the atrial wall defect using an autologous pericardial patch (Figure 2, B and $C$ ). After de-airing the heart, the crossclamp was removed, and we snared the right pulmonary artery to prevent blood loss from the lung side of the transected atrium. We then weaned the patient from cardiopulmonary bypass, ventilating only the left lung and keeping the right lung deflated for the subsequent lobectomy. Some blood flow remained out of the lung side of the transected atrium, presumably from bronchial arterial flow. We over-sewed the transected atrium to control blood flow and keep the surgical field clear. We performed a wedge resection of the left lower lobe while the left lung was ventilated, with a brief apneic period for the actual stapling of the wedge resection, and then decannulated. We then completed the right lower lobectomy (Figure 2, D). There were no intraoperative complications, and the postoperative course was unremarkable. Pathology results showed that the surgical margin was negative and there was no viable tumor in the bilateral lung lesions. We treated the patient with aspirin for 6 months postoperatively. At the last follow-up at 6 months postoperatively, a CT scan of the chest, abdomen, and pelvis showed no evidence of recurrent disease.

\section{DISCUSSION}

Complete resection is important for successful pulmonary metastatectomy. ${ }^{4}$ In a case like this, with extensive tumor extension into the left atrium, open atrial resection provides less risk of cutting into or clamping onto the tumor and thus likely reduces the risk of tumor embolus, stroke, or a positive atrial resection margin.

To minimize the risk of tumor embolus while manipulating the tumor in the left atrium, we opted for a clamshell incision. This is a strategy borne from double-lung transplantation and applied toward the removal of bilateral or sizable tumors in the thorax. ${ }^{5}$

\section{CONCLUSIONS}

Open atrial resection may be a viable option to achieve complete resection for pulmonary metastasis with extensive invasion in the left atrium.

\section{References}

1. Billingsley KG, Burt ME, Jara E, Ginsberg RJ, Woodruff JM, Leung DH, et al Pulmonary metastases from soft tissue sarcoma: analysis of patterns of diseases and postmetastasis survival. Ann Surg. 1999;229:602-12.

2. van Geel AN, Pastorino U, Jauch KW, Judson IR, van Coevorden F, Buesa JM, et al. Surgical treatment of lung metastases: The European Organization for Research and Treatment of Cancer-Soft Tissue and Bone Sarcoma Group study of 255 patients. Cancer. 1996;77:675-82.

3. Potter DA, Glenn J, Kinsella T, Glatstein E, Lack EE, Restrepo C, et al. Patterns of recurrence in patients with high-grade soft-tissue sarcomas. J Clin Oncol. 1985;3: 353-66.

4. Pastorino U, Buyse M, Friedel G, Ginsberg RJ, Girard P, Goldstraw P, et al. Long term results of lung metastasectomy: prognostic analyses based on 5206 cases. $J$ Thorac Cardiovasc Surg. 1997;113:37-49.

5. Bains MS, Ginsberg RJ, Jones WG II, McCormack PM, Rusch VW, Burt ME, et al The clamshell incision: an improved approach to bilateral pulmonary and mediastinal tumor. Ann Thorac Surg. 1994;58:30-3. 